\title{
Localisation of aphidicolin-induced break points in Holstein-Friesian cattle (Bos taurus) using RBG-banding
}

\author{
Viviana Rodriguez ${ }^{\mathrm{a}}$, Silvia Llambía ${ }^{\mathrm{a} *}$, Alicia Postiglioni ${ }^{\mathrm{a} *}$, \\ Karina GuevarA ${ }^{\mathrm{a}}$, Gonzalo RinCón ${ }^{\mathrm{a}}{ }^{\text {, Gabriel Fernández }}{ }^{\mathrm{b}}$, \\ Beatriz Mernies ${ }^{\mathrm{b}}$, María Victoria Arruga ${ }^{\mathrm{c}}$ \\ a Department of Cell and Molecular Biology, Genetic Section, \\ Laboratory of Genetics Analysis in Domestic Animals, \\ Faculty of Veterinary, UDELAR, A. Lasplaces 1550 CP 11600, \\ Montevideo, Uruguay \\ ${ }^{\mathrm{b}}$ Department of Animal Production, Animal breeding Section, \\ Faculty of Veterinary, UDELAR, Uruguay \\ ${ }^{c}$ Laboratory of Cytogenetics and Molecular Genetics, \\ Faculty of Veterinary, Zaragoza University, Spain
}

(Received 21 November 2001; accepted 1st July 2002)

\begin{abstract}
Fragile sites (FS) seem to play a role in genome instability and may be involved in karyotype evolution and chromosome aberrations. The majority of common fragile sites are induced by aphidicolin. Aphidicolin was used at two different concentrations $(0.15$ and $0.30 \mu \mathrm{M})$ to study the occurrence of FS in the cattle karyotype. In this paper, a map of aphidicolin induced break points and fragile sites in cattle chromosomes was constructed. The statistical analysis indicated that any band with three or more breaks was significantly damaged $(P<0.05)$. According to this result, 30 of the 72 different break points observed were scored as fragile sites. The Pearson correlation test showed a positive association between chromosome length and the number of fragile sites $(r=0.54)$. On the contrary, 21 FS were identified on negative $\mathrm{R}$ bands while 9 FS were located on positive $\mathrm{R}$ bands.
\end{abstract}

cattle / chromosome / fragile sites / aphidicolin

\section{INTRODUCTION}

Fragile sites are non-random chromosomal breaks or gaps observed in cells under folate-deficient conditions or in cells grown in the presence of

* Correspondence and reprints

E-mail: sllambi@adinet.com.uy; alipos@adinet.com.uy 
certain mutagens, carcinogens or clastogens such as caffeine, 5-azacytidine and aphidicolin. They seem to play a role in genome instability and may be involved in the aetiology of "in vivo" chromosome aberrations and karyotype evolution [15].

In man, they are classified in rare and common fragile sites (FS), according to their frequency in the population and to the tissue culture conditions required to induce their cytogenetic expression. The major group of rare fragile sites comprises the folate-sensitive group including the human fragile $\mathrm{X}$ (FRAXA) associated with the fragile $\mathrm{X}$ syndrome, the most common form of hereditary mental retardation. Common fragile sites (c-fra) are found at specific loci on most human chromosomes and are probably present in all individuals. Since c-fra are expressed spontaneously only at a very low frequency in metaphase plates (less than 5\%) it is necessary to expose cells to specific reagents such as aphidicolin (APC), which induces many common fragile sites. APC is a diterpenoid mycotoxin, which specifically inhibits eukaryotic DNA polymerase alpha and beta [15]. APC induced fragile sites are well documented in humans but have been studied only sporadically in mammals and domestic animals, mainly in primates, pigs, cats, and cattle $[4,6,9,12]$.

Riggs et al. [12] located APC induced fragile sites on pig GTG-banded chromosomes and demonstrated a dependence between APC-induced breakage events and "in vivo" chromosome rearrangements. Also it has been proposed that interbands between heterochromatic and euchromatic regions may be more susceptible to breakage. On the contrary, Fundia et al. [4], found no significant correlation between heterochromatic regions or structural changes and fragile sites, in two New World Monkey species.

Cytogenetic studies in Uruguayan Holstein-Friesian and Uruguayan Creole cattle performed with cells cultured in the absence of any chemical inducer, revealed the presence of a fragile site on Xq31 [6,9]. Rincón et al. in 1997 [13] found a significant differential expression of this fragile site, between cells cultured in RPMI 1640 and in TC199 $(0.05>P>0.01)$. This finding suggested that the bovine FRA Xq31 does not represent a folate-sensitive fragile site. Lately, we began to test different concentrations of APC $(0.24 \mu \mathrm{M} ; 0.3 \mu \mathrm{M})$ to induce the expression of chromosomal break points in cattle breeds, with special emphasis on bovine chromosome $\mathrm{X}$ and 1 , both involved in different chromosome rearrangements [6,9].

The purpose of the present paper was to analyse the effect of aphidicolin on cattle chromosomes and to locate the induced break points on the RBG banded karyotype. To our knowledge this was the first attempt to establish a map of aphidicolin induced fragile sites in cattle chromosomes (Bos taurus, BTA). 


\section{MATERIALS AND METHODS}

\subsection{Cytogenetic analysis}

Three Holstein-Friesian cows T06 (A); 525 (B); 660 (C) from a dairy farm in Uruguay were analysed cytogenetically to locate aphidicolin-induced chromosome break points.

Peripheral whole blood $(0.2 \mathrm{~mL})$ from each animal was cultivated in $5 \mathrm{~mL}$ of RPMI 1640 (Sigma) medium, supplemented with $10 \%$ foetal bovine serum, penicillin $\left(100 \mathrm{IU} \cdot \mathrm{mL}^{-1}\right)$, streptomycin $\left(100 \mu \mathrm{g} \cdot \mathrm{mL}^{-1}\right)$, and phytohemagglutinin $\left(0.2 \mu \mathrm{g} \cdot \mathrm{mL}^{-1}\right)$ for $72 \mathrm{~h}$ at $38^{\circ} \mathrm{C}$ according to a modified protocol [7]. Colchicine $\left(0.004 \mathrm{mg} \cdot \mathrm{mL}^{-1}\right)$ was added $2 \mathrm{~h}$ before harvesting the cultures. For dynamic RBG banding 5-bromo-2'-deoxyuridine $\operatorname{BrdU}\left(20 \mu \mathrm{g} \cdot \mathrm{mL}^{-1}\right)$ was incorporated into the cells $6 \mathrm{~h}$ before harvesting. Air-dried chromosome slides were incubated with Hoechst $33258\left(4 \mathrm{mg} \cdot \mathrm{L}^{-1}\right)$ in $0.9 \% \mathrm{NaCl}$ during $30 \mathrm{~min}$ and exposed to a black-ray lamp for $15 \mathrm{~min}$ [7]. Three cultures were processed for each sample, one without aphidicolin (control) and two with aphidicolin at a final concentration of $0.15 \mu \mathrm{M}$ and $0.3 \mu \mathrm{M}$. All cultures were set up simultaneously with identical batches of complete culture medium. The six cultures were APC-induced for the last $24 \mathrm{~h}$ of culture.

Break point positions were recorded on a diagrammatic representation of the RBG banded bovine karyotype [2].

\subsection{Statistical analysis}

Considering the hypothesis that each chromosome band should have a nearly equal likelihood of displaying a break, a chi square test with the Yates correction was applied [11].

The relationship between the chromosome relative length, and the number of fragile sites on each chromosome was calculated using the Pearson correlation test.

\section{RESULTS}

\subsection{Cytogenetic studies}

Figure 1 shows RBG banded partial metaphases with aphidicolin induced break points.

Fifty metaphases per animal were analysed in each control culture, and for the three animals analysed a normal female complement $2 \mathrm{n}=60$, XX without any structural abnormality was found.

A total of 223 metaphase plates were analysed in the aphidicolin-induced cultures, and 217 breaks were recorded being distributed over 72 sites (Tab. I). 

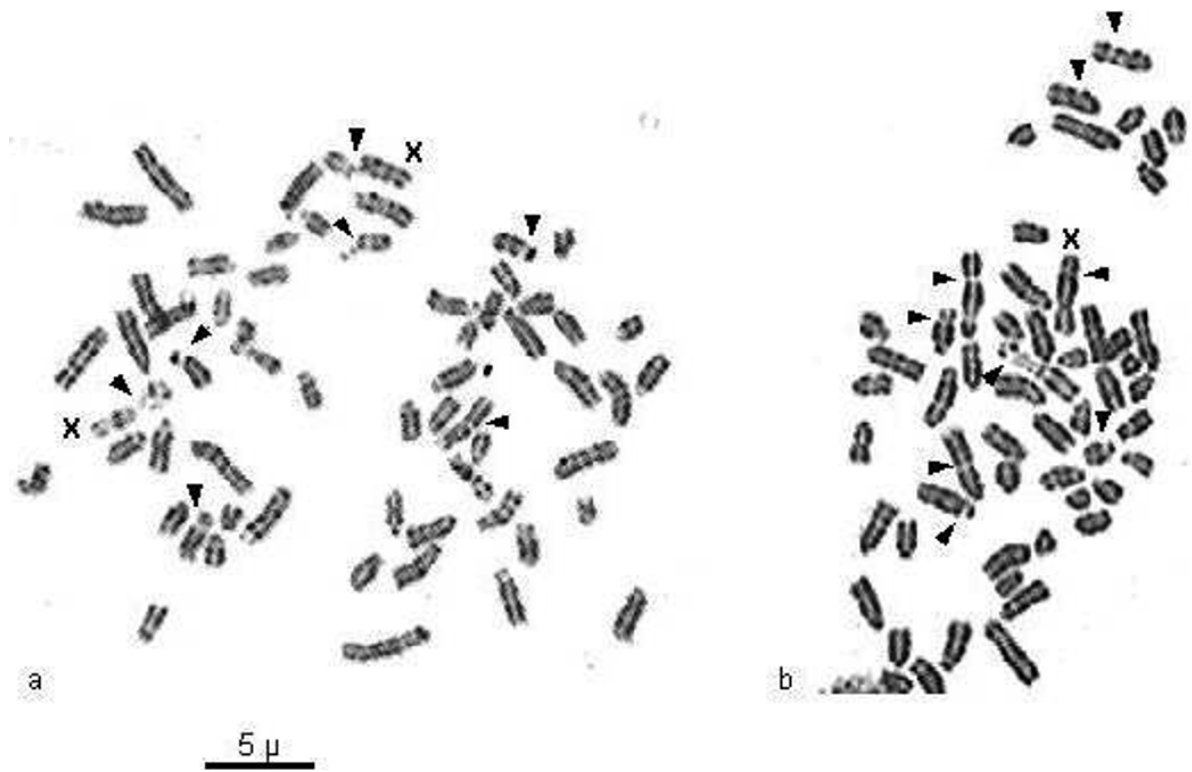

Figure 1. APC pre-treated partial RBG banded metaphases. Arrow heads indicate break points.

Table I. Number of metaphases analysed and break point percentage observed in each APC treated cell culture.

\begin{tabular}{ccccc}
\hline & \multicolumn{2}{c}{ Number of metaphases } & \multicolumn{2}{c}{ Breaks (\%) } \\
\hline & $0.15 \mu \mathrm{M}$ & $0.30 \mu \mathrm{M}$ & $0.15 \mu \mathrm{M}$ & $0.30 \mu \mathrm{M}$ \\
Animals & APC & APC & APC & APC \\
\hline A & 93 & 40 & $181(92.3)$ & $2(9.5)$ \\
B & 40 & 15 & $10(5.1)$ & $10(47.6)$ \\
C & 15 & 20 & $5(2.5)$ & $9(42.9)$ \\
Total & 148 & 75 & $196(100)$ & $21(100)$ \\
\hline
\end{tabular}

\subsubsection{APC induced break points on the cattle RBG banded idiograms}

Taking into account the cattle RBG banded idiograms, a map of APCinduced break points and fragile sites was drawn (Fig. 2).

Based on a total of 399 bands from the standard RBG banded haploid karyotype [2], and assuming that each band has an equal probability of breakage, the expected number of breaks per band for the 217 aberrations observed in this study is 0.54 . The statistical analysis indicated that any band with three or more breaks was significantly damaged $\left(\chi^{2}=7.11\right.$; d.f. $\left.1 ; P<0.05\right)$. According to this result, 30 of the 72 different break points observed were scored as fragile sites (Tab. II). 

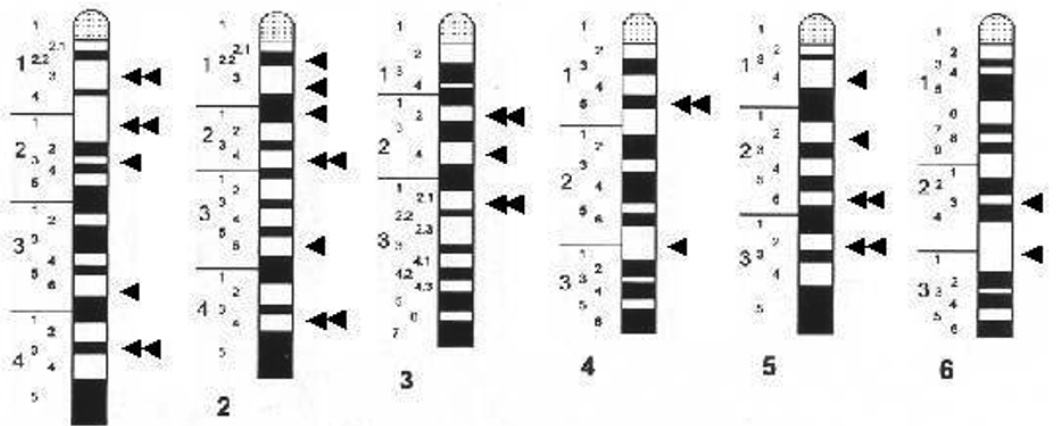

1
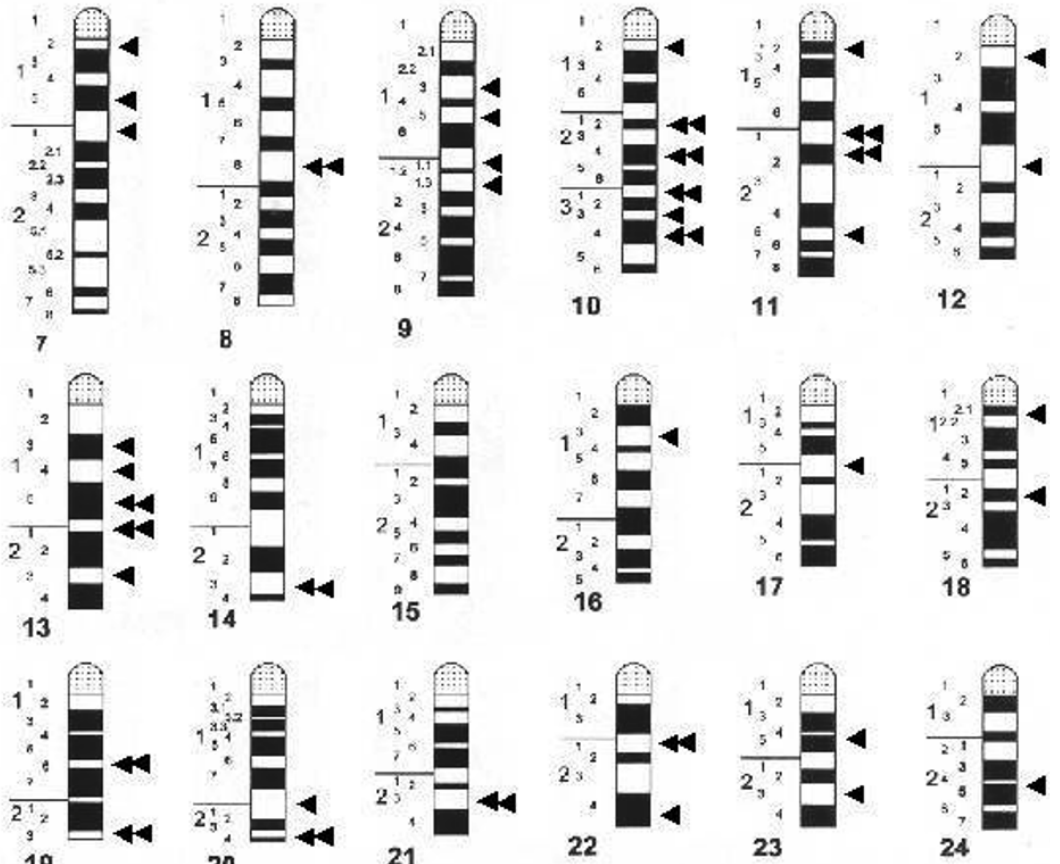

21
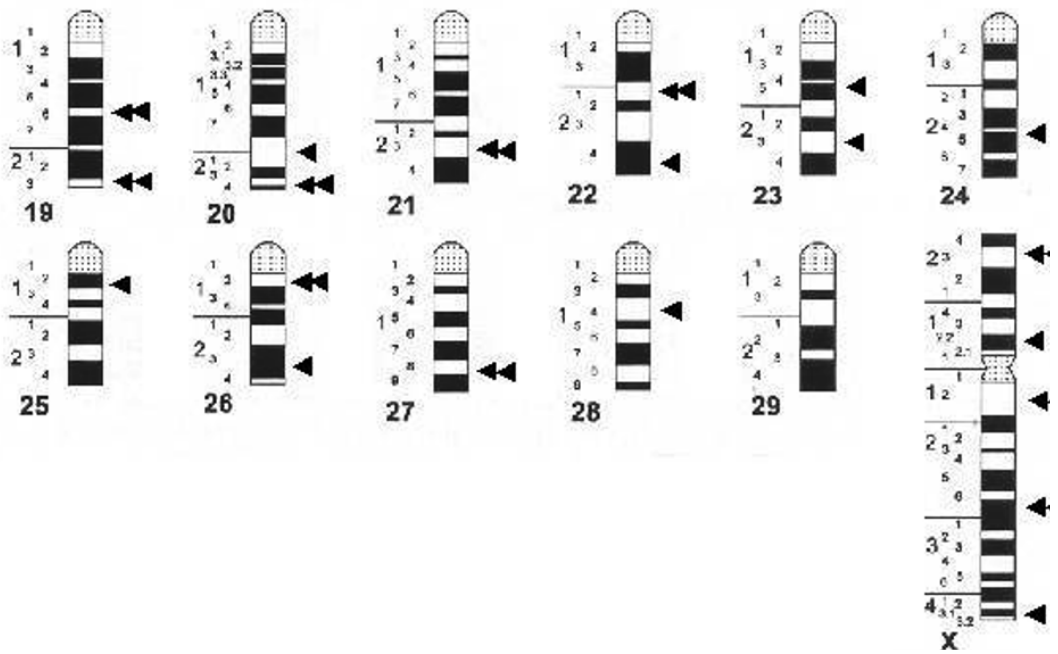

Figure 2. Localisation of break points $(4)$ and fragile sites $(44)$ on the diagrammatic representation of the RBG banded cattle karyotype according to ISCNDB 2000. 
Table II. Aphidicolin-induced fragile sites in bovine chromosomes.

\begin{tabular}{cl}
\hline Number of breaks & Fragile site locations \\
\hline 3 & 1q43R+, 8q18R-, 10q31R-, 10q34R+, 13q15R+, 13q21R-, \\
& $14 \mathrm{q} 23 \mathrm{R}-$, 19q23R-, 21q23R-, 26q12R-, Xp23R- \\
4 & $2 \mathrm{q} 44 \mathrm{R}-, 10 \mathrm{q} 24 \mathrm{R}+, 11 \mathrm{q} 21 \mathrm{R}-, 11 \mathrm{q} 22 \mathrm{R}+$, 27q18R- \\
5 & $2 \mathrm{q} 24 \mathrm{R}-, 3 \mathrm{q} 321 \mathrm{R}-, 4 \mathrm{q} 15 \mathrm{R}+, 5 \mathrm{q} 26 \mathrm{R}-$, 20q24R+, Xq12R- \\
6 & $19 \mathrm{q} 16 \mathrm{R}-, 22 \mathrm{q} 21 \mathrm{R}-$ \\
7 & $10 \mathrm{q} 22 \mathrm{R}+$ \\
9 & $3 \mathrm{q} 22 \mathrm{R}-, 5 \mathrm{q} 32 \mathrm{R}-$ \\
11 & $1 \mathrm{q} 21 \mathrm{R}-$ \\
14 & $1 \mathrm{q} 13 \mathrm{R}-, \mathrm{Xq} 31 \mathrm{R}+$ \\
\hline
\end{tabular}

Of these 30 fragile sites, 21 are located on negative $R$ bands and 9 on positive $\mathrm{R}$ bands.

The Pearson correlation test showed a positive association between the chromosome length and the number of fragile sites $(r=0.54 ; P<0.001)$.

\section{DISCUSSION}

Aphidicolin induces break-points, gaps and fragile sites in various mammalian species $[11,15]$. We observed that this genotoxical element also produces significant damage on cattle chromatin structure. Dynamic RBGbanding permitted to locate APC-induced break points and to discriminate between early and late replicating euchromatic regions in the cattle karyotype. Thirty of the 72 break points observed were scored as having a significant damage (three or more breaks) and were therefore considered as fragile sites $(P<0.05)$. This finding agreed with data reported on pig chromosomes, for which four or more breakage events were considered as possible significantly damaged [11].

Le Beau et al. [5] analysed APC induced c-fra in human chromosomes and established a model in which c-fra involve sequences that replicate late in the $\mathrm{S}$ phase or are slow to replicate. This supports our observations, i.e., there are 21 fragile sites located on $\mathrm{R}$ negative bands corresponding to late replicating euchromatin versus 9 fragile sites located on $\mathrm{R}$ positive bands corresponding to early replicating euchromatin.

On the contrary, Di Berardino et al. [3], studied BrdU induced breakpoints in cattle chromosomes and determined a positive correlation $(r=+0.76)$ under the assumption of proportionality between the number of breaks and chromosome length. This agrees with our data since we obtained a positive 
Pearson correlation $(r=+0.54)$ between APC-induced fragile site number and relative chromosome length. Despite the correlation value obtained, we cannot discard the fact that other factors such as chromosome structure and nucleotide DNA sequences involved in either early or late replication regions might be involved.

In the RBG banded cattle idiograms showing the APC induced break points, the largest chromosome BTA1, presents three fragile sites $(1 \mathrm{q} 13 \mathrm{R}-, 1 \mathrm{q} 21 \mathrm{R}-$, $1 \mathrm{q} 43 \mathrm{R}+$ ) with sites $1 \mathrm{q} 13$ and $1 \mathrm{q} 21$ displaying the highest number of breaks. The BTAX presents three fragile sites (Xp23R-, Xq12R-, Xq31R+). These fragile sites may be involved in chromosome rearrangements such as inversions or transpositions; these rearrangements have been described for the chromosomal evolution of BTAX [14]. Moreover, an X-autosomal translocation, involving BTA1 and BTA23, has also been described in cattle and is associated with fertility problems $[1,8]$.

The exposure at different APC concentrations $(0.15 \mu \mathrm{M}, 0.30 \mu \mathrm{M})$ in lymphocyte cultures, revealed a differential behaviour. The highest number of FS was observed at $0.15 \mu \mathrm{M}$ but it should be noted that the number of metaphase plates scored at $0.30 \mu \mathrm{M}$ was much lower (Tab. I). These results agreed with those reported for human cell cultures in which higher levels of aphidicolin cause such widespread chromosomal fragmentation that the chromosomes are no longer cytogenetically identifiable [10].

A differential percentage of break points among the three animals was also observed. Cytogenetic analysis in pigs has shown that the number of fragile sites varies with different animals, suggesting an animal effect in the case of APC induced fragile sites [12]. In our case, a higher number of animals and metaphase spreads will be needed to better understand the effect of aphidicolin on cattle lymphocyte cultures.

In conclusion, we identified and located APC induced break points on cattle RBG banded chromosomes, thus distinguishing between fragile sites (defined as highly damaged regions) and simple break points.

\section{ACKNOWLEDGEMENTS}

The authors wish to thank Miss Iris Hernández for the technical assistance.

This paper was financed by grants of: CIDEC, CSIC, PEDECIBA in Uruguay and AECI in Spain.

\section{REFERENCES}

[1] Basrur P.K., Reyes E.R., Farazmand A., King W.A., Popescu P.C., X-autosome translocation and low fertility in a family of crossbred cattle, Anim. Reprod. Sci. 67 (2001) 1-16. 
[2] Di Berardino D., Di Meo G.P., Gallagher D.S., Hayes H, Iannuzzi L., ISCNDB: International system for chromosome nomenclature of domestic bovids, Cytogenet. Cell. Genet. 92 (2001) 283-299.

[3] Di Berardino D., Iannuzzi L., Di Meo G., Localization of BrdU-induced break sites in bovine chromosomes, Caryología 36 (1983) 285-292.

[4] Fundia A., Gorostiaga M., Murdy M., Expression of common fragile sites in two Ceboidea Species: Saimiri boliviensis and Alouatta canaya (Primates: Platyrrihini), Genet. Sel. Evol. 32 (2000) 87-97.

[5] Le Beau M.M., Rassool F.V., Neilly M.E., Espinosa R., Glover T.W., Smith D.I., McKeithan T.W., Replication of a common fragile site, FRA3B, occurs late in S phase and is delayed further upon induction: implications for the mechanism of fragile site induction, Hum. Mol. Genet. 7 (1998) 755-761.

[6] Llambí S., Guevara K., Rincón G., Nuñez R., Arruga M.V., Postiglioni A., Aphidicolin-induced fragile sites in Bos taurus lymphocyte cultures (a preliminary study), Hung. J. Anim. Prod. 48 (1999) 117-119.

[7] Llambí S., Postiglioni A., Frequencies and cytomorphological manifestation of sexual X-chromosome fragility (Fra Xq3.1) in Holstein-Friesian, Arch. Zootech. 45 (1996) 203-208.

[8] Mayr B., Korb H., Kiendler G., Brem G., Reciprocal X;1 translocation in calf, Genet. Sel. Evol. 30 (1998) 305-308.

[9] Postiglioni A., Llambí S., Núñez R., Guevara K., Rincón G., Expresión de sitios frágiles comunes (csf) en el genoma de los bovinos Criollos del Uruguay. Estudios preliminares, in: Memorias del XVI Congreso Panamericano de ciencias veterinarias, 1998, Vol. 262, Santa Cruz de la Sierra, Bolivia, TL.b115.

[10] Richards R.I., Fragil and unstable chromosomes in cancer: causes and consequences, TIG 17 (2001) 339-345.

[11] Riggs P.K., Chrisman C.L., Identification of aphidicolin-induced fragile sites in domestic pig chromosomes, Genet. Sel. Evol. 23 (1991) Suppl. 1, 187s-190s.

[12] Riggs P.K., Kuczck T., Chrisman C.L., Bidwell C.A., Analysis of aphidicolininduced chromosome fragility in the domestic pig (Sus scrofa), Cytogenet. Cell. Genet. 62 (1993) 110-116.

[13] Rincón G., Llambí S., Postiglioni A., Expression of X chromosome fragility in Holstein-Friesian cattle: a preliminary study, Genet. Sel. Evol. 29 (1997) 395-401.

[14] Robinson T., Harrinson R., Ponce de León S., Davis S., Elder F., A molecular cytogenetic analysis of $\mathrm{X}$ chromosome repatterning in the Bovidae: transpositions, inversions, and phylogenetic inference, Cytogenet. Cell. Genet. 80 (1998) 179-184.

[15] Sutherland G., Baker E., Richards R., Fragile sites still breaking, Trends Genet. 14 (1998) 501-506. 